\title{
Customer Relationship Management (CRM) Capabilities \& Building a Sustainable Competitive Advantage in Mobile Phone Operators in Jordan
}

\author{
Mohammad Salem Alshura ${ }^{1}$ \\ ${ }^{1}$ World Islamic Sciences and Education University, Amman, Jordan \\ Correspondence: Mohammad Salem Alshura, World Islamic Sciences and Education University, Amman, Jordan. \\ E-mail:mhmadshura@yahoo.com
}

Received: December 30, 2017

Accepted: February 10, 2018

Online Published: February 25, 2018

doi:10.5539/ijbm.v13n3p262

URL: https://doi.org/10.5539/ijbm.v13n3p262

\begin{abstract}
Purpose -This study is trying to investigate the effect of customer relationship management (CRM) capabilities on building a sustainablecompetitive advantage in the mobile phone operators in Jordan. It is intended to develop a valid measurement model of (CRM) capabilities, and to explore the key factors of CRM that lead to a competitive edge.
\end{abstract}

Design/methodology/approach - Questionnaire survey was used to gather data. In order to develop a reliable and valid measurement model of CRM capabilities, questionnaire survey were conducted and hypotheses were tested by utilizing the technique of multiple regression analysis in addition to reliability and multicollinearity tests.

Findings - A three-capabilities (customer interaction management, customer relationship upgrading, and customer win-back) measurement model of CRM is developed and tested. Furthermore, results support the hypothesized influences of these three capabilities influence on firms' building a sustainable competitive advantage.

Practical implications - This study provides a useful measurement mode of CRM capabilities that managers can use to evaluate the status in quo of CRM of their firms. Managers may also improve their CRM programs more effectively and efficiently by deploying such strategic resources of firms to build a sustainable competitive advantage.

Originality/value - The paper addresses significant gaps in the current literature by taking a capability view of CRM, developing a valid measurement model of CRM capabilities, and examining how possession of important CRM resources influences the effective deployment of CRM capabilities.

Keywords: Customer relationship management (CRM), CRM capabilities, competitive advantage, mobile phone

\section{Introduction}

Technology revolution, particularly World Wide Web (www) was a significant opportunity for firms to interact directly with their customers, customized their increasing and changeable needs, and provides better solutions to build a strong long-term relationship with them, deliver high-quality products and services which was not available before (Winer, 2001). Today, CRM is still being used most regularly by firms that based on two distinguishing characteristics: customer service and technology. According to Anderson (Andersen, 2001), financial services sector, high tech corporations, and telecom industry are the three sectors of business that depend mostly on CRM and use it to obtain great advantages. Telecom industry particularly tracks the level of customers' satisfaction and what they looking for in terms of changes and individualized features.

$(\mathrm{CRM})$ is considered as a holistic strategy that can help organizations to become customer oriented and as a valuable capability to remain stable in today's competitive business world. (CRM) is considered as a holistic strategy that can help organizations to become customer oriented and as a valuable capability to remain stable in today's competitive business world.Possession of heterogeneous resources such as market-based assets (relational and intellectual assets) provide the firm with a vital source of competitive advantage (Barney, 2001); (Srivastava et al., 1998). little research has focused on how optimally exploit those resources to suit market 
conditions, and contribute enhancing the firm's competitive advantage.based on CRM capabilities, we address this gap and argue that possession of such resources impact the firm's performance which in turn influence competitive advantages. Specifically, we will examine the role of (CRM) capabilities in building a sustainable competitive advantage.Furthermore, studies of customer relationship management have revealed that many business organizations failed to effectively manage their customer relationship management program ( Reinartz et al., 2004).Some studies concluded that these firms faltered because they failed to deploy the CRM resources they possessed to build superior capabilities in managing customer relationships and achieve competitive advantages (Day and Van , 2002); (Morgan et al. , 2009); (Plakoyiannaki and Tzokas, 2002). Therefore, it is urgently needed for these firms to learn how to develop and strengthen their CRM capabilities. However, little is known about what exactly CRM capabilities are, and its role in improving competitive advantage.

The bottom line, this study seeks to address this important gap and contributing to existing literature through a contribution of CRM literature by taking a capability view of CRM; develop a valid measurement model of CRM capabilities; test the influence CRM capabilities on building a sustainable competitive advantage in mobile phone operators in Jordan. This provides new empirical evidence for dynamic capability perspective by demonstrating the importance of customer relating capabilities in deploying firm resources to build sustainable competitive advantages of a firm (Eisenhardt and Matin, 2000).

The remainder of this paper is organized as follows: section 2.Providesthetheoretical framework of this study and hypotheses developmentbased on extensive literature review .Section 3. Discuss the research methodology. Next, hypotheses testing results is discussed in section 4. This is followed by Discussions and implications in section 5. Development and validation process, and hypotheses testing. Finally, we draw some limitations and future research direction in section 6.

\subsection{Research Questions}

1) What is the influence of CIMC on building a sustainable competitive advantage?

2) What is the influence of CRUC on building a sustainable competitive advantage?

3) What is the influence of CWBC on building a sustainable competitive advantage?

\subsection{Objectives of the Study}

General: This study seeks to identify the strong customer-relating capabilities; develop a valid measurement model of CRM capabilities; and test the influence CRM capabilities on competitive advantage.

Specific: The specific objectives this study is aimed at are stated as below:

1) To bring out the influence of CIMC on building a sustainable competitive advantage.

2) To bring out the influence of CRUC on building a sustainable competitive advantage.

3) To bring out the influence of CWBC on building a sustainable competitive advantage.

\section{Theoretical Framework and Hypotheses Development}

The resource-based view emphasized that sustained competitive advantages emanate from valuable, rare, inimitable and non-substitutable (VRIN) resources (Barney, 2001); (Barney, 1991). CRM capabilities lead to superior performance over time that leads to sustained competitive advantage (Morgan et al. , 2009); (Makadok, 2001).

Strong customer-relating capabilities are one of the most significant marketing capabilities that are posited to enable organizations to make use of their related customer relational resources to build sustainable competitive advantages (Day, 2000).

Therefore, this paper concentrate on CRM capabilities and proposes that company's CRM capabilities can positively influence a competitive advantage by combining such valuable capabilities as customer interaction management capability (CIMC); customer relationship upgrading capability (CRUC); and customer win-back capability (CWBC).

\subsection{CRM Capabilities}

CRM is a cross-functional organizational process that focuses on establishing, maintaining, and enhancing long-term relationships with attractive customers (Payne and Frow, 2005).

CRM capabilities are embedded in CRM activities in organizational processes, and they reflect an organization's skills and accumulated knowledge to "identify attractive customers and prospects, initiate and maintain relationships with attractive customers, and leverage these relationships into customer level profits" (Morgan et 
al. , 2009).Thus, CRM capabilities are affected by major CRM activities like customer relationship upgrading (e.g. cross-selling and up-selling), customer relationship win-back (re-establishing relationships with lost but profitable customers), and customer interaction management (e.g. customer identification, customer acquisition and customer retention) ( Reinartz et al., 2004).

Therefore, we can treat CRM capabilities as a multi-dimensional construct consisting of three components customer interaction management capability; (2) customer relationship upgrading capability; and (3) customer win-back capability In this study, we hypothesized that these three CRM capabilities positively impact building a sustainable competitive advantage. The research model investigates the effects WIMC, CRUC, and CWBC(independent variables) as dimensions of CRM capabilities on building sustainable competitive advantages (dependent variables). Figure 1 summarized the theoretical framework of this study.

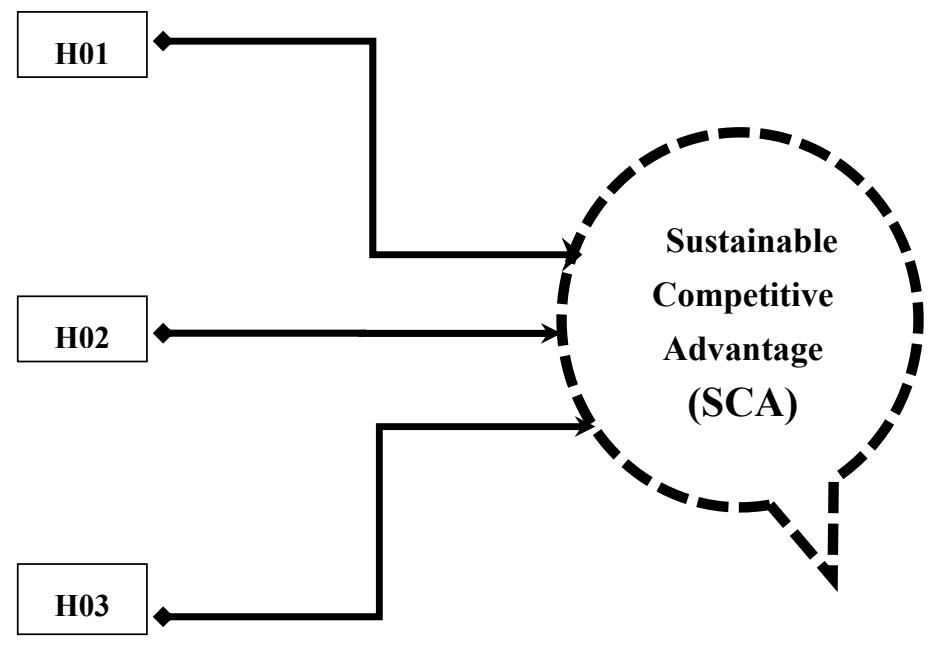

Figure 1. Theoritical framework

\subsection{Customer Interaction Management Capability}

CIMC refers to "the skills that organizations use to identify acquire and retain profitable customers" (Yonggui and Fing, 2012).Superior customer-relating capabilities result from the organizational culture that considers customers' need a priority, the organization system that promotes customer relationship building and the information technology that enables customer information acquisitions and analysis[ (Day and Van , 2002); (Day, 2003)].The regular meeting with customers to learn their current and potential needs for new products; creating relationships with key customers; maintaining an interactive two-way communication with customers; continual dialogue with each customer and use well-developed methods to improve our relationships, and maintaining a relationship with key customers, will enable firms to maintain a large base of customers, and thus create sustainable competitive advantages.

\subsection{Customer Relationship Upgrading Capability}

CRUC refers to "the skills that firms use for up-selling (sell more expensive items, upgrades) and cross-selling (sell additional products or service) to existing customers based on scientific customer data analysis" (Yonggui and Fing, 2012). Firms with such capabilities: measuring customers' satisfaction systematically and frequently; formalizing procedures for up-selling to valuable customers; formalizing procedures for cross-selling to valuable customers, and extending "share of customers" with high-value customers systematically, might achieve a sustainable competitive advantage.

\subsection{Customer Win-Back Capability}

CWBC refers to "the skills firms use to re-establish the relationship with lost or inactive but profitable customers" (Yonggui and Fing, 2012), since a loss of those customers will have a huge negative impact on firm performance in the long run (Reichheld and Sasser, 1999), and the skill to get back the profitable but lost customers is called as customer win-back capability. Apologizing or compensate in time for the inconvenience or lost that caused by the company to customers; following up a systematic approach to reestablish relationships 
with valued lost and inactive customers; taking the corrective action immediately when we find that customers are unhappy with the appropriateness of product or service; maintaining a positive relationships with the departing or unattractive customer on a regular basis. All these activities will likely help firms to build a sustainable competitive advantage.

\subsection{Competitive Advantage}

Peteraf (1993) defines competitive advantage as sustained above-average returns. Fulfilling a sustainable competitive advantage can help mobile phone companies to counter the intense competition in the telecom sector, and establishing a self-sustaining position in the marketplace. Developing and maintaining the relationships with customer is vital for obtaining the competitive advantage according to (Kale, 2004). (Porter, 1980), indicated that a competitive advantage grows fundamentally out of value an organization is able to produce for its consumers that exceeds the firm's cost of creating it. Organizations' ability to adjust themselves to the customer needs quickly is one of the most requirements of competitiveness. Increasingly competitions make organizations have more relationships and contacts with the customers in the market.

CRM and its capabilities is a strategic organizational process through which the company can face competitors, create value for the consumers, and gaining many other excellent benefits. From the above discussion, the researcher concluded that the better usage of firms' CRM capabilities positively influences building sustainable competitive advantages. Based on the objective of this study as well as the study's research model; the following hypotheses are developed and will be tested:

Hypothesis One (H1): Customer interaction management capability does not influence building a sustainable competitive advantage in mobile phone operators firm in Jordan.

Hypothesis Two (H2): Customer relationship upgrading capability does not influence building a sustainable competitive advantage in mobile phone operators firm in Jordan.

Hypothesis Three (H3): Customer win-back capability does not influence building a sustainable competitive advantage in mobile phone operators firm in Jordan.

\section{Research Methodology}

In order to evaluate how CRM capabilities affect building a sustainable competitive advantage in Jordan's mobile phone operators, a quantitative approach will be conducted, where data will be gathered through a questionnaire. The population of the study consisted of 3 mobile companies (Zain Jo, Orange, \& Umniah) that operate in the Jordanian telecom sector. In the sampling stage, the study is based on a convenience sample of 150 employees working in the marketing department in these companies. 150 questionnaires were distributed to the employees working in the marketing departments in the headquarters of the three companies(50 for each) in the capital of Jordan; Amman. Participants were briefed about the purpose of the study, and given enough time to fill out the questionnaire. 135 questionnaires were collected; five of those were discarded because they were incomplete. 130 found usable for this study.

\subsection{Survey Instrument}

As this study sought to test the proposed theoretical model, some of the survey instruments were adapted and modified from the previous studies (Yonggui and Fing, 2012); (Day and Van , 2002). The survey contained several constructs related to the CRM capabilities will be measured (CIMC, CRUC, and CWBC). Prior to administering the survey, it was reviewed by four experts from the marketing and business professors for clarity and applicability to the topic investigated. Overall, the survey designed 16 questions to gauge the effect of CRM capabilities on building a sustainable competitive advantage. CIMC includes 5 items, CRUC includes 4 items, CWBC includes 4 items, and building a sustainable competitive advantage was measured through 3 items.

In order to test the research hypotheses, collected data will help examine the relationship between the variables of interest to the study. The data were analyzed using Statistical Package for Social Sciences (SPSS). A measure of multiple regression analysis will be conducted, in addition to reliability and multicollinearity tests. The results will provide a basis for accepting or rejecting the hypotheses and answering the research questions. In order to examine the effect of CRM capability factors on the competitive advantage, 5 points Liker scale systems were used. Scale varies between strongly disagree $=1$ and strongly agree $=5$

\subsection{Reliability Statistic}

The measure of reliability shows that the questions asked in the study demonstrate an inconstant consistently. In order to conclude the reliability based on internal consistency, Cronbach's alpha is applied. The minimum standard of 0.7 is set by Nunnally to pass this test (Nunnally, 1978). The Cronbach's alpha for CIMC, CRUC, 
CWBC, and competitive advantage is $0.83,0.79,0.78$, and 0.81 higher than 0.7 . as shown in Table 1. Consequently, the internal consistency of the measurement of all variables exists. These results show that these variables can be used for this study.

Table 1. Constructs and reliability tests

\begin{tabular}{lll}
\hline Constructs & No.of items & Cronbach's alpha \\
\hline CIMC & $\mathbf{5}$ & $\mathbf{0 . 8 3}$ \\
CRUC & 4 & $\mathbf{0 . 7 9}$ \\
CWBC & 4 & $\mathbf{0 . 7 8}$ \\
Competitive advantage & $\mathbf{3}$ & $\mathbf{0 . 8 1}$ \\
\hline
\end{tabular}

\section{Hypotheses Testing Results}

In order to test the research hypotheses, multiple regression analysis was used. Moreover, the level of significance ( $\alpha$-level) was chosen to be 0.05 and the probability value (p-value) obtained from the statistical hypotheses test is considered to be the decision rule to accept or reject the null hypotheses (Creswell, 2009).If $\mathrm{p}$-value is $\leq$ to $\alpha$-level, the null hypothesis will be rejected and the alternative hypothesis will be supported. if the $p$-value is $>$ the $\alpha$-level, the null hypothesis cannot be rejected and the alternative hypothesis will not be supported. In addition, normality of the independent variables and the absence of multi co-linearity problem (a case of multiple regression in which the independent variables are themselves highly correlated) were checked.

Most of the values should be inside the adequate ranges for normality as suggested by (Pallant, 2005). To achieve this, tolerance and Variance Inflation Factor (VIF) were investigated; a VIF value of 5 or 10 and above and a tolerance of $<0.20$ indicate that variables are multicollinearity, as shown in table 2. Results in table 2 indicates that VIF ranges between 1.405 and 1.566 which are well-below five, and the tolerance values range between 0.638 and 0.713 which are above 0.20 ., These factors show that there is no evidence of multicollinearity problem in the regression model.

Table 2. VIF and tolerance for the independent variables

\begin{tabular}{llc}
\hline Constructs & VIF & Tolerance \\
\hline CIMC & 1.405 & 0.713 \\
CRUC & 1.566 & 0.638 \\
CWBC & 1.434 & 0.696 \\
\hline
\end{tabular}

Pearson correlation matrix was calculated for the independent variable dimensions to check the correlation between them. Table 3 shows the results. A value of 0.75 and above suggests a high correlation between the variables according to (Sekaran, 2003). The results in the above table, are all below 0.75 and thus don't suggest high correlation between the variables. Therefore, these findings also show that there is no evidence of multicollinearity problem.

Table 3. The matrix of Pearson correlation

\begin{tabular}{lc}
\hline Constructs & \multicolumn{2}{c}{ Pearson correlation coefficients } \\
& CIMCCRUCCWBC \\
\hline CIMC & $\mathbf{0 . 5 0 3}$ \\
CRUC & $\mathbf{0 . 4 2 7}$ \\
CWBC & $\mathbf{0 . 5 1 5}$ \\
\hline
\end{tabular}

The results of testing the three hypotheses are presented in Table 4. As indicated, there is a positive correlation between CRM capabilities and building a sustainable competitive advantage since the multiple correlation coefficient $\mathrm{R}=0.432$. The adjusted $\mathrm{R}^{2}$ relates to the generalizability of the model. It allows us to generalize the results taken from the respondents to the whole population. In this case, it equals 0.185 . The results showed that F-ratio of these data is equal to 16.623 , which is statistically significant at $p<0.05$. Therefore, we conclude that there is a statistically significant effect of CRM capabilities and building a sustainable competitive advantage. 
Table 4. Regression analysis results

\begin{tabular}{llllllll}
\hline Constructs & $\mathbf{R}$ & $\mathbf{R}^{2}$ & $\boldsymbol{\beta}$ & $\mathbf{F}$ & $\operatorname{Sig}(\mathbf{f})$ & $\mathbf{t}$ & $\operatorname{Sig}(\mathbf{t})$ \\
\hline CIMC & 0.432 & 0.185 & 0.210 & 16.623 & 0.000 & 2.918 & 0.004 \\
CRUC & & & 0.112 & & & 1.480 & 0.140 \\
CWBC & & & 0.206 & & & 2.840 & 0.005 \\
\hline
\end{tabular}

The $\beta$ indicates to the individual contribution of each predictor (independent variable) to the model, if other predictors are held constant. Table 4 shows the standardized coefficients for each frame work dimensions. The values of $\beta$ for CIMC, CRUC, and CWBC are $0.210,0.112,0.206$ respectively, which are all positive. The level of effect of these variables depends on the $\beta$ value; the higher $\beta$ value the higher the effect on the dependent variable. It can be concluded from the values of $\beta$ that the variable that has the highest contribution in the model is CIMC, followed by CRUC and finally the CWBC.The results of the study indicated that the three capabilities of CRM proposed by the framework (CIMC, CRUC, and CWBC) played a significant role with varying degrees in building sustainable competitive advantages in Jordanian mobile operators.

Thus, the first hypothesis, hypothesis One (H1): of this study states that"Customer interaction management capability does not influence building a sustainable competitive advantage in mobile phone operators firm. This hypothesis was rejected; it was found that the CIMC had a positive significant impact on building a sustainable competitive advantage. The second hypothesis stated that "hypothesis Two (H2): Customer relationship upgrading capability does not influence building a sustainable competitive advantage in mobile phone operators firm is also rejected; it was found that the CRUC had a positive significant impact on building a sustainable competitive advantage .The third hypothesis, hypothesis Three (H3): "Customer win-back capability does not influence building a sustainable competitive advantage in mobile phone operators firm" was rejected as this factor was found to have a positive impact on building sustainable competitive advantage. Reference (Muhammad Nouman et al., 20015); (Yonggui and Fing, 2012) agree with the findings of this study.

\section{Discussions and Implications}

Capturing of CRM capabilities, and fulfill customer needs enables organizations to gain more competitive advantage and respond to customers at real time for developing new products and services. This research study explored the conceptualization and dimensionality of CRM capabilities and developed a valid measurement model of CRM capabilities. It was found that CRM capabilities reflected a firm's skills and knowledge to routinely establish, maintain, upgrade and re-establish beneficial relationships with attractive customers, and they were composed of customer interaction management capability, customer relationship upgrading capability and customer win-back capability .Our results also revealed a significant and direct relationship between firms' CRM capabilities and building a sustainable competitive advantage. Findings that are consistent with previous research (Kim et al., 2012); ( Reinartz et al., 2004).

In spite of the importance of deploying customer-relating resources for obtaining a sustainable competitive advantage has been widely recognized. Only a few empirical studies (if any) have been conducted to test the effect of CRM capabilities on competitive advantage, this research filled this gap by showing the importance of CRM capabilities in improving firm competitive advantage .Also, the results enrich the extant literature of the resource-based view by revealing that possession of valuable CRM capabilities. In order to build a strong sustainable competitive advantage, managers had to acquire strong CRM capabilities as (CIM, CRUC, and CWB), and deploy them well in organizational process. Besides, research framework also enabled us to understand the effectiveness and importance of each these capability for building and sustaining competitive advantage as well.

\section{Limitations and Future Research Direction}

Results clearly indicated that CRM capabilities were significantly and positively associated with sustainable competitive advantage, and the study also revealed that the possession of such capabilities resources such as customer interaction management, customer relationship upgrading, and customer win-back contributed to strongly in building a sustainable competitive advantage.

However, as with all research, there were some limitations that should be noted. First, it should be noted that other CRM components could have an effect on sustainable competitive advantage such as technology. Second, the focus was solely on the telecom sector; therefore, empirical work should consider alternate industries such as banking sector to ascertain the stability of the findings. Third, the variation in the market environment of different countries might influence the types of strategies adopted by mobile companies and the impacts of these 
strategies on building sustainable competitive advantages. Given that we developed the CRM capability scale and tested the framework in Jordan context, future research could validate the measured model and test the framework in different national cultural contexts to establish a global generalizability.

Fourth the CRM in practice was to some extent is very complicated, future studies could also examine the moderating effect of environmental factors such as firm size and market growth rate on the relationship between CRM capabilities and sustainable competitive advantage.

\section{Acknowledgements}

I would like to pay special thankfulness, warmth, and appreciation to Dr. Abdelrahim .M. Zabadi who assisted me at every point during the planning and development of this research work. His willingness to give his time so generously has been very much appreciated.

\section{References}

Andersen, P. H. (2001). Relationship development and marketing communication: An integrative model. Journal of Business \& Industrial Marketing, 16, 167-187. https://doi.org/10.1108/08858620110389786

Barney, J. B. (1991). Firm resources and sustained competitive advantage. Journal of Management, 17(1), 19-120. https://doi.org/10.1177/014920639101700108

Barney, J. B. (2001). Resource-based theories of competitive advantage: a ten-year retrospective on the resource-based view. Journal of Management, 27, 643-50. https://doi.org/10.1177/014920630102700602

Creswell, J. (2009). Research Design: Qualitative, Quantitative, and Mixed Methods Approaches (3rd ed). Sage Publications, Thousand Oaks.

Day \& Van. (2002). Superiority in customer relationship management: consequences for competitive advantage and performance. Marketing Science Institute, Working Paper, 102-123.

Day, G. S. (2003). Creating a superior customer-relating capability. MIT Sloan Management Review, 44, 77-82.

Eisenhardt, K. M., \& Martin, J. A. (2000). Dynamic capabilities: what are they? Strategic Management Journal, 21, 1105-21. https://doi.org/10.1002/1097-0266(200010/11)21:10/11<1105::AID-SMJ133>3.0.CO;2-E

Kale, S. (2004).CRM failure and the seven deadly sins. Marketing Management, 13(5), $42-46$.

Kim, M., Park, J. E., Dubinsky, A. J., \& Chaiy, S. (2012) Frequency of CRM implementation activities: A customer-centric view. Journal of Services Marketing, 26(2), 83-93. https://doi.org/10.1108/08876041211215248

Makadok, R. (2001). Toward a synthesis of the resource-based and dynamic-capability views of rent creation. Strategic Management Journal, 22(5), 387-401. https://doi.org/10.1002/smj.158

Morgan, N. A., Vorhies, D. W., \& Mason, C. H. (2009). Market orientation, marketing capabilities, and firm performance. Strategic Management Journal, 30, 909-20. https://doi.org/10.1002/smj.764

Muhammad, N. S., Naveed, A., \& Alamdar, H. (2015). Impact of customer relationship management capabilities on organizational performance; moderating role of competition intensity. Journal of Business and Management Review (Nigerian Chapter), 3(3), 28-47. https://doi.org/10.12816/0014506

Nunnally, J. C. (1978). Psychometric Theory (2nd ed.). New York: McGraw-Hill.

Pallant, J. (2005). SPSS Survival Manual: A Step Guide to Data Analysis Using SPSS for Windows Version 12. Chicago: Open University Press.

Payne, A., \& Frow, P. (2005). A strategic framework for customer relationship management. Journal of Marketing, 69(4), 167-76. https://doi.org/10.1509/jmkg.2005.69.4.167

Peteraf, M. A. (1993). The cornerstones of competitive advantage: A resource-based view. Strategic Management Journal, 14, 179-191. https://doi.org/10.1002/smj.4250140303

Plakoyiannaki, E., \& Tzokas, N. (2002). Customer relationship management: a capabilities portfolio perspective. Journal of Database Management, 9(3), 228. https://doi.org/10.1057/palgrave.jdm.3240004

Porter, M. E. (1980). Competitive strategy. The Free Press.

Reichheld, F. F., \& Sasser, W. E. Jr. (1999). Zero defections: quality comes to services. Harvard Business Review, $68,105-11$.

Reinartz, W., Krafft, M., \& Hoyer, W. D. (2004). The customer relationship management process: its measurement and impact on performance. Journal of Marketing Research, 293-305. 
https://doi.org/10.1509/jmkr.41.3.293.35991

Sekaran, U. (2003). Research Methods for Business: A Skill Building Approach (4th ed.). John Wiley \& Sons, Ltd., Hoboken.

Srivastava, R. K., Shervani, T. A., \& Fahey, L. (1998). Market-based assets and shareholder value: a framework for analysis. Journal of Marketing, 62(1), 2-18. https://doi.org/10.2307/1251799

Wang, Y. G., \& Feng, H. (2012). Customer relationship management capabilities: Measurement, antecedents and consequences. Management Decision, 50(1), 115-129. https://doi.org/10.1108/00251741211194903

Winer, R. S. (2001). A framework for customer relationship management. California Management Review, 43, 89-105. https://doi.org/10.2307/41166102

\section{Copyrights}

Copyright for this article is retained by the author(s), with first publication rights granted to the journal.

This is an open-access article distributed under the terms and conditions of the Creative Commons Attribution license (http://creativecommons.org/licenses/by/4.0/). 